\title{
Combined biomass inventory in the scope of REDD (Reducing Emissions from Deforestation and Forest Degradation)
}

\author{
Daniel Plugge $\left.\right|^{\mid *}$, Thomas Baldauf ${ }^{\mid *}$, Harifidy Rakoto \\ Ratsimba", Gabrielle Rajoelison" and Michael Köhl'"
}

\author{
Correspondence: \\ Daniel Plugge \\ Johann Heinrich von Thuenen-Institute (VTI), Institute for World \\ Forestry, Leuschnerstrasse 91, 21031 Hamburg, Germany \\ E-mail: daniel.plugge@vti.bund.de
}

\begin{abstract}
This paper presents an approach for combined biomass inventories in the scope of future REDD regimes. The focus is set on a sound and reliable method for measuring and monitoring the current state of carbon stocks and their changes over time. A reliable framework for measuring, reporting and verification is urgently needed to ensure the integrity and credibility of REDD efforts in general and REDD in the post-2012 agreement which is assumed to be approved at COP 16 in Mexico in December 2010. The proposed approach was developed and successfully implemented in Madagascar within a multi-institutional REDD project, i.e., REDD-FORECA. It combines a multi-temporal remote sensing approach incorporating satellite sensors from medium to very high resolution with a terrestrial cluster sampling design, which proved to be operational for the whole spectrum from highly fragmented to pristine forest areas. This combination was implemented by a multi-phase sampling approach. The inventory is designed for the prerequisites of a continuous forest inventory to facilitate the quantification of possible $\mathrm{CO}_{2}$ reductions over time. The first field-assessments were accomplished in 2007 and 2008, and resulted in estimates of aboveground biomass on single tree level. Statistical upscaling procedures were utilised to aggregate these estimates on several levels. The results of the introduced methodology are presented and discussed.
\end{abstract}

\section{RÉSUMÉ}

Cet article présente une approche concernant les inventaires de biomasse combinés dans le cadre des futurs régimes REDD. Elle porte sur une méthode fiable et avérée pour mesurer et contrôler l'état actuel des stocks de carbone et leur évolution dans le temps. Un système fiable de mesure, de suivi et de vérification est nécessaire pour garantir l'intégrité et la crédibilité des efforts investis dans REDD en général d'une part et du mécanisme REDD dans les accords post-2012 devant être approuvé à Mexico en décembre 2010 lors de la COP 16, d'autre part.
Dans la mesure où REDD doit pouvoir être appliqué par I'ensemble des pays en voie de développement, l'accent a été mis en particulier sur la possibilité de transférer la méthode en tenant compte des particularités nationales et régionales des divers pays concernés. L'approche proposée a été développée et mise en œuvre à Madagascar avec succès dans le cadre d'un projet REDD (REDD-FORECA) impliquant plusieurs institutions. Elle associe une approche basée sur la télédétection multitemporelle, intégrant des capteurs de moyenne à très haute résolution avec un plan d'échantillonnage terrestre en 'cluster'. Elle s'est avérée opérationnelle sur l'intégralité du spectre des surfaces forestières, depuis les parcelles extrêmement fragmentées aux forêts intactes. Cette possibilité d'adapter la méthode à une large variété d'états de la forêt a été testée et vérifiée. Cet article met de plus en lumière la possibilité de détecter et de quantifier le déboisement et la dégradation des forêts. La méthode présentée permet d'estimer de manière fiable la biomasse forestière et son évolution dans le temps, à un coût total et avec des erreurs d'échantillonnage raisonnables. Cela a été possible grâce à une démarche d'échantillonnage à plusieurs phases en combinant des phases de télédétection avec une phase terrestre d'inventaire. Un contrôle rigoureux des erreurs d'échantillonnage lors de chacune de ces phases est essentiel pour générer des bénéfices dans un mécanisme REDD. L'inventaire est conçu de façon à remplir les pré-requis de tout inventaire forestier continu afin de faciliter la quantification des éventuelles réductions de $\mathrm{CO}_{2}$. Les premières mesures sur le terrain qui se sont déroulés en 2007 et en 2008 ont permis d'estimer la biomasse au-dessus du niveau du sol. Pour dériver ces estimations à des niveaux d'agrégation plus élevés, des procédures ascendantes (upscaling) ont été utilisées. Les résultats de la méthodologie employée sont présentés et discutés.

KEYWORDS: Combined inventory, remote sensing, biomass, Reducing Emissions from Deforestation and Forest Degradation (REDD), Madagascar. 


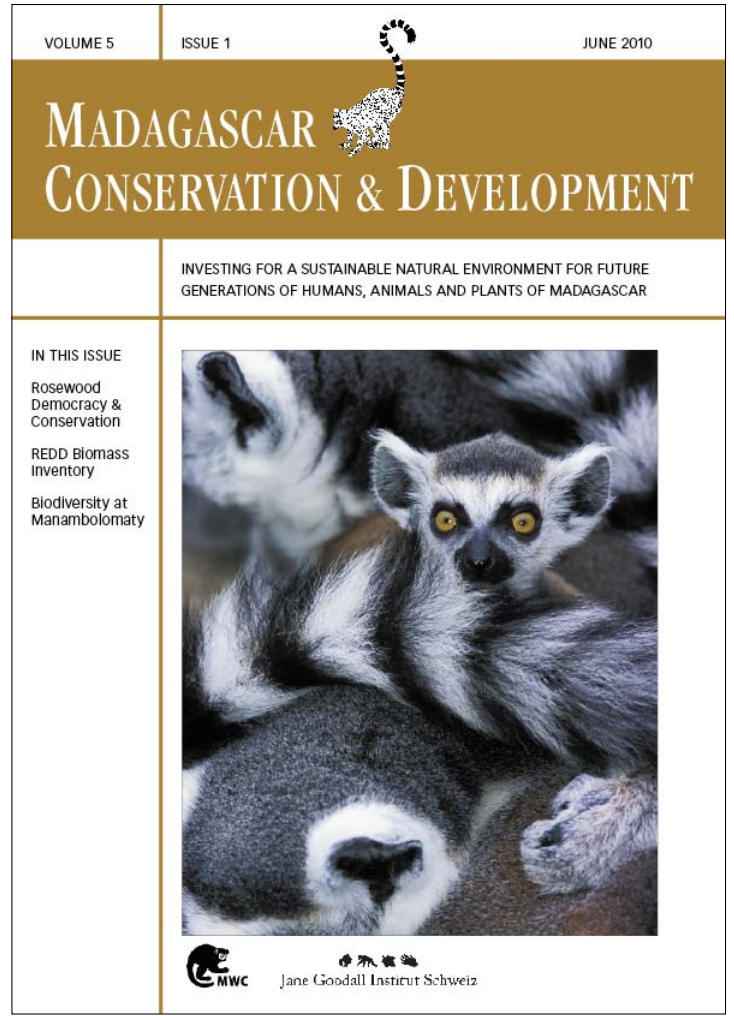

Madagascar Conservation \& Development is the journal of Madagascar Wildlife Conservation (MWC) and the Jane Goodall Institute (JGI Switzerland). It is produced under the responsibility of these institutions. The views expressed in contributions to MCD are solely those of the authors and not those of the journal editors or the publishers.

All the Issues and articles are freely available at http://www.mwc-info.net/en/services/journal.htm

\section{Contact Journal MCD}

info@journalmcd.net for general inquiries MCD funding@journalmcd.net for supporting the journal

Journal Madagascar Conservation \& Development Institute and Museum of Anthropology University of Zurich

Winterthurerstrasse 190

$\mathrm{CH}-8057$ Zurich, Switzerland

contact@mwc-info.net for general inquiries

Postfach 2701

CH-8021 Zürich, Switzerland

Logement 11, Cité Andohaniato

Antananarivo 101, Madagascar

info@janegoodall.ch for general inquiries JGI

\section{$2 \pi$ Jane Goodall Institut Schweiz}

Jane Goodall Institute Schweiz

Postfach 2807

8033 Zürich

switzerland 
MOTS CLEFS : inventaire combine, télédétection, biomasse, réduction des émissions du déboisement et la dégradation forestière (REDD), Madagascar.

\section{INTRODUCTION}

According to estimates of the Intergovernmental Panel on Climate Change (IPCC) an annual total of 1.6 billion tons of carbon are released worldwide by land-use change activities, of which a major part results from deforestation and forest degradation (Denman et al. 2007). Following the Stern Report (Stern 2007) carbon emissions from land-use change accumulate to nearly one-fifth of today's total annual emissions, most of which can be traced back to tropical deforestation. The avoidance of deforestation and forest degradation is not accepted so far as an eligible action in the current commitment period of the Kyoto Protocol, i.e., 2008-2012. In 2005 the Eleventh Session of the Conference of Parties (COP 11) to the United Nations Framework Convention on Climate Change (UNFCCC) initiated a process for considering a policy for reduced emissions from deforestation and forest degradation (REDD).

REDUCING EMISSIONS FROM DEFORESTATION AND FOREST

DEGRADATION (REDD). Some economical incentives for reducing the emissions of greenhouse gases (GHG) exist in the Kyoto Protocol. In the articles 3.3 and 3.4 the benefit of forests as carbon sinks are considered (UNFCCC 1998) and in the Clean Development Mechanism measures for afforestation and reforestation can be accounted for generation of credits. These financial measures reward the function of forests as carbon sinks or carbon sequestration by local to regional re- or afforestation activities. In contrast, REDD focuses mainly on the maintenance of forest carbon stocks through compensation of potential direct or indirect economic benefits of deforestation and forest degradation on a national level. As developing countries, sheltering the major part of the existing tropical forests, have shown high rates of deforestation in the recent past, the process REDD is expected to become an important element for reduction of GHG emissions into the atmosphere. However, effective incentives leading to a reduction of deforestation and forest degradation are still a topic of ongoing discussions. To ensure the integrity and credibility of REDD efforts in general and REDD in the post-2012 agreement a reliable framework for measuring, reporting and verification is urgently needed (UNFCCC 2007). As a consequence thereof, the parties at COP 15 in Copenhagen acknowledged a decision on the methodological guidance for activities relating to REDD and therein request the establishment of robust and transparent national forest monitoring systems (UNFCCC 2009). It is assumed that a legally binding agreement on REDD will be integrated in a post-2012 agreement at COP 16 in Mexico in December 2010 Nevertheless, each country choosing REDD as an option for mitigating GHG emissions needs to set up its own national strategy and monitoring system that has to adhere UNFCCC standards. Implementing a viable REDD regime involves several steps:

(1) Initiating a system for the assessment of forest carbon stocks and their change over time;

(2) quantifying the amount of reduced $\mathrm{CO}_{2}$ emissions, which qualifies for accounting;

(3) identifying and ranking of the relevant causes for human impact on forests in order to derive effective measures to combat the degradation of forests;
(4) definition of a reference level (i.e., baseline), against which the changes of carbon stocks in forests are set off; and

(5) implementing a scheme for the transfer of benefits to local actors.

PILOT PROJECT REDD-FORECA. REDD-FORECA is a multi-partnership pilot project in Madagascar that was set up to develop methodological approaches to monitor accountable reductions of GHG emissions due to deforestation and forest degradation activities, to develop possible incentives to realise these reductions, and to integrate the results into the political decision-making process of Madagascar. In REDD-FORECA the German von Thünen-Institute (VTI) and the Malagasy scientific partner ESSA Forêts collaborate with the 'Swiss Foundation for Development and International Cooperation' (Intercooperation) and the 'Gesellschaft für Technische Zusammenarbeit' (GTZ), as well as with various cooperation partners in Madagascar, i.e., inter alia local and national forest authorities. The focal point of the pilot project was set on natural forests as plantations or managed forests are not likely to be a part of REDD.

CARBON FLUXES. AS REDD focuses on the maintenance of already existing carbon stocks in natural forests five major carbon pools are to be considered: (1) Aboveground biomass, (2) below-ground biomass, (3) dead wood, (4) litter, and (5) soil organic matter (IPCC 2006). By increasing at least one pool, while maintaining the other pools forests become a carbon sink. However, respecting the complexity of natural systems, all these five carbon pools are highly interdependent and in a steady state of flux (Longdoz et al. 2004, Nabuurs 2004).

Currently there is a contradictory debate on the amount of carbon transferred by the decay of living biomass, i.e., pools 1 and 2, to the atmosphere and to soils, i.e., pool 5. Despite growing interest on this topic, there are no long-term studies in tropical areas on soil carbon fluxes that could allow reliable inferences to the scope of REDD. Thus, the following brief overview on different positions in this debate concentrates on studies from temperate regions. While some publications suggest an increase of organic soil components and thus an increase of carbon sequestered by soils (Freibauer et al. 2009), others report no significant changes in soil carbon or even a release of soil carbon to the atmosphere. Schlesinger and Lichter (2001) studied soil carbon in Pinus taeda stands and found high transfer rates of organic carbon in the litter layer, i.e., pool 4, but an absence of carbon accumulation in the mineral soil. They conclude that a significant, long-term net carbon sequestration in soils is an unlikely event. Bellamy et al. (2005) analysed data of the National Soil Inventory in England and Wales, which were assessed between 1978 and 2003. They report a mean annual release of 0.6 percent of the existing soil carbon stock, which compensates with high probability the carbon sequestration by soils. In accordance with the IPCC Good Practice Guidance for National Greenhouse Gas Inventories (IPCC 2006) it was assumed that carbon uptake and carbon release by soils is at equilibrium and that it is justifiable to exclude this pool from accounting. Furthermore, we assume that the carbon sequestration by living biomass in natural forests is on the long run in balance with the carbon offset by the decay of dead organic matter. Thus, natural forests are neither a carbon sink nor a carbon source. 
For these reasons the presented methodology will focus on the quantification of living aboveground biomass, which can be subsequently transformed into carbon stock. Changes of the carbon stock are induced by either a total loss of biomass due to deforestation and associated land-use changes or by a net-reduction of biomass stock, i.e., forest degradation. Hence the REDD-FORECA project in Madagascar had inter alia the objective to assess changes of forest area and changes of living biomass stock.

A multitude of methods exist to fulfil this objective. This article illustrates both the development of a methodology for the assessment of forest carbon stocks and their changes over time, and the possibilities of quantification of the amount of reduced $\mathrm{CO}_{2}$ emissions, which qualifies for accounting. Furthermore, the results after the methodology's appliance are presented and discussed.

\section{INTRODUCTION INTO THE METHODOLOGY}

To assess changes in forest area and of living biomass on a national scale combined inventories, i.e., the combination of remote sensing (RS) data and in-situ assessments, have been advised by IPCC (IPCC 2006) and proven to be cost efficient and operational on the one hand and to lead to reliable results on the other hand (Bowden et al. 1979, Scott and Köhl 1994, Achard et al. 2002, IPCC 2003). For this purpose the top-down approach is a commonly used and operational methodology on national level. In the following paragraphs the subsequent steps of this multi-phase approach, as illustrated in Figure 1, are outlined.
In a first step a full coverage of the country's area (wall-to-wall map) can be obtained by remote sensing imagery data. The quality of such data depends on its spatial, spectral, radiometric and temporal resolutions. The wide variety of RS sensors and their specific characteristics have been classified by DeFries et al. (2006) for the particular needs of REDD (Table 1).

The information of the wall-to-wall map can be specified by the usage of sensible auxiliary data on e.g., climate, topography or vegetation classes to derive broad regions of the country's area. Within these regions thematic classes, i.e., non-forest and forest areas can be obtained in a second step by further classifying the remote sensing data. The non-forest and forest areas are considered to be homogeneous groups or strata (Remote Sensing Phase 1, in Figure 1). In general the stratification of an area of interest into sub-areas or strata has the objective to form homogenous sub-units. In most situations, stratified probability sampling is likely to yield more precise population estimates (i.e., estimates with smaller standard errors) than non-stratified probability sampling with the same sample size.

To obtain information on the development of a country's forest area the changes over time between the forest and non-forest areas have to be analysed by applying change detection algorithms for archive and present data (time 0 , time 1, in Figure 1).

In contrast to a national forest inventory (NFI), a combined inventory in the scope of REDD needs to concentrate mainly on forest areas that show ample changes in their spatial extent. The use of change detection algorithms integrated in multi-tem-

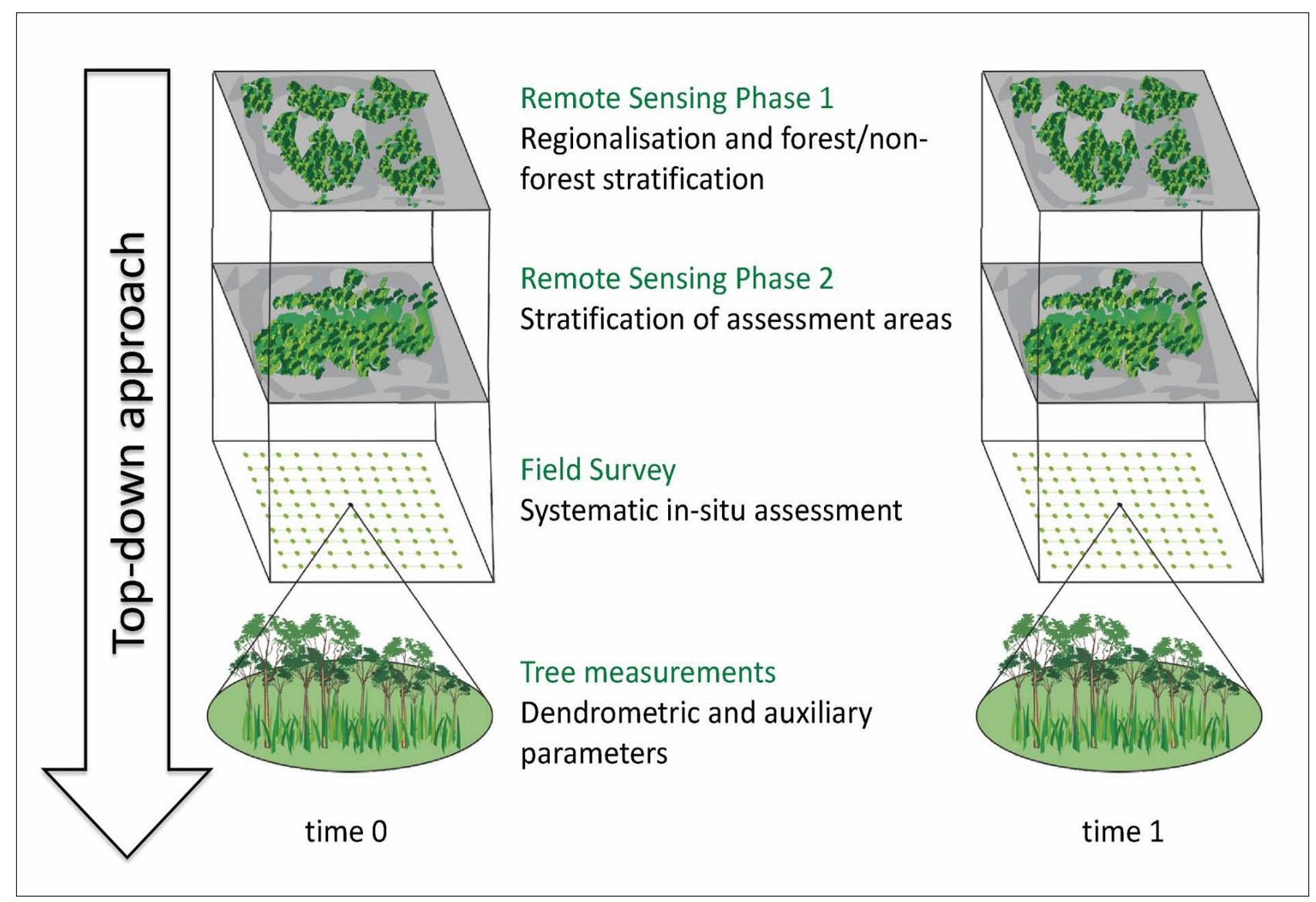

FIGURE 1. Top-down approach for a combined inventory on national scale. 
TABLE 1. Utility of optical sensors with different resolutions in deforestation monitoring (after DeFries 2006).

\begin{tabular}{|l|l|l|l|}
\hline $\begin{array}{l}\text { Sensor Resolution } \\
(<5 \mathrm{~m})\end{array}$ & Examples of Current Sensors & Utilility for Monitoring & Cost \\
\hline $\begin{array}{l}\text { High } \\
(10-60 \mathrm{~m})\end{array}$ & Landsat, SPOT HRV, AWiFSLISS III, CBERS & $\begin{array}{l}\text { Validation over small areas of results from coarser } \\
\text { resolution analysis }\end{array}$ & Very high \\
\hline $\begin{array}{l}\text { Medium } \\
(250-1000 \mathrm{~m})\end{array}$ & MODIS, SPOT Vegetation & $\begin{array}{l}\text { Consistent global annual monitoring to identify large } \\
\text { clearings ( }>10-20 \text { ha) and locate "hotspots" for further } \\
\text { analysis with high resolution }\end{array}$ & $\begin{array}{l}\text { Low/medium (historical) to } \\
\text { medium high (recent) }\end{array}$ \\
\hline $\begin{array}{l}\text { Data from optical sensors have been widely used for deforestation monitoring. Data from Lidar and Radar (ErS 1/2 SAR, JERS-1, ENVISAT-ASAR and ALOS } \\
\text { PALSAR) have demonstrated to be useful in project studies, however, so far are not widely used operationally for tropical deforestation monitoring. An } \\
\text { exception is the use of SRTM data, which were acquired by an active RADAR sensor. }\end{array}$ \\
\hline
\end{tabular}

poral data can be combined with socio-economic data (e.g., accessibility, number and distribution of settlements), which allows detecting both possible 'hot spots' with high rates of deforestation and forest degradation, and undisturbed areas. Assessment areas, where the in-situ assessments are carried out, can be selected from these hot spots following specified criteria.

In a third step the assessment areas can be further analysed to identify different strata inside the forest area (e.g. closed forest, open forest) through the utilization of high or very high resolution imagery. The combination of different sensors on different scales for this purpose is commonly utilized and proposed by e.g., FAO (2007).

In a next step the design of the in-situ assessment has to be chosen. A multitude of options for the allocation of sample plots (SP) within the strata, like for example, simple random sampling or systematic random sampling, exist and can be found in the specific literature (Loetsch et al. 1973, synnott 1979, Adlard 1990, IPCC 2006, Köhl et al. 2006). Nevertheless, especially for pilot assessments, where little is known on the characteristics of the forest, a systematic sampling design of the in-situ phase is advised (Saket et al. 2002). Here the sample plots are allocated on a systematic grid in each stratum, thus facilitating the assessment of dendrometric and auxiliary data to obtain information on living aboveground biomass.

To enhance the cost efficiency and feasibility of this approach and taking into account the difficulties of hard to access, remote areas of tropical forests, it is advised to apply cluster sampling. An introduction into the methods and statistical peculiarities of cluster sampling can be found in the literature (Loetsch et al. 1973, Cochran 1977, Köhl et al. 2006 Mandallaz 2008). A measure for the efficiency of cluster sampling is the intra-cluster-correlation coefficient (ICC), which is presented for each of the assessment areas in the results chapter (see Results).

\section{APPLIED METHODOLOGY}

For the present pilot project in Madagascar an assessment method for monitoring current state and changes of forest carbon stock has been developed and applied. This method combines the capacities of remote sensing techniques to assess spatial data on forest areas with the potential of sample based field surveys to capture even small changes in forest carbon stock. A detailed illustration of this applied methodology is shown in the Supplementary Material.

To assess natural forest carbon stocks and their changes over time it is indispensable to define 'forest'. From the several existing definitions (UNFCCC 2001, Schoene et al. 2007) the minimum benchmarks defined in the Marrakesh Accords were chosen, in order to realise the inclusion of small forest fragments severely threatened to be finally deforested as well as the dry forests in southern Madagascar. These are (i) a minimum area of 0.05 hectare, (ii) a tree crown cover of more than $10 \%$ and, (iii) the potential to present trees that reach at least two meters height in-situ. To the knowledge of the authors Madagascar itself has not yet decided on a definition of forest for the scope of REDD.

Figure 1 shows the subsequent steps of the applied top-down approach. The implementations of these steps in Madagascar are described in the following.

REGIONALISATION OF THE LAND AREA OF MADAGASCAR.

There are a number of factors influencing the amount of aboveground biomass stocks in forests, resulting in a broad range of these in a single country. However, only some factors are feasible for breaking down a country's land area into homogeneous groups, thus dividing the whole range of possible forest aboveground biomass (AB) into specific, consistent compartments. The aim of the regionalisation in this project was to reduce cost and to increase the accuracy of field assessments. Within the 'Good Practice Guidance for Land Use, Land-Use Change and Forestry' (GPG-LULUCF) (IPCC 2003) stratification rules for broad forest categories related to aboveground biomass stocks are presented, which can be applied worldwide. These rules are shown in Table 2 for tropical forests.

In order to assign these IPCC categories to Madagascar the following input data have been used (see Figure 2): (i) Data of the Moderate Resolution Imaging Spectroradiometer (MODIS), (ii) data of the Shuttle Radar Topography Mission (SRTM) and, (iii) information on climate.

A regionalisation of Madagascar was performed using a supervised classification of these data. This common technique uses RS-data with terrestrial reference data in order to assign discrete or continuous classes to areas. Within the classification process, in this case a maximum likelihood classifier was used, statistical parameters were derived from the RS-data and resultant features thereof (Lillesand et al. 2004).

RS - data generally has to be pre-processed before performing analyses, i.e., geometric and radiometric corrections. These processes lower the estimated errors in the results. Additionally, the use of passive sensors demands, especially in the tropics, the masking of clouds and shadows in RS-data, as these areas cannot be further processed.

Time series of MODIS data were applied for the monitoring of forest cover changes by deforestation on large areas and the identification of hot spots. In doing so, the use of expensive, very 
TABLE 2. Aboveground biomass stock in tons per hectare per forest formation (adapted from IPCC 2003).

\begin{tabular}{|c|c|c|c|c|c|c|}
\hline \multicolumn{7}{|c|}{ Tropical Forests } \\
\hline & Wet & $\begin{array}{l}\text { Moist with Short Dry } \\
\text { Season }\end{array}$ & $\begin{array}{l}\text { Moist with Long Dry } \\
\text { Season }\end{array}$ & Dry & Montane Moist & Montane Dry \\
\hline & $P>2000$ & \multicolumn{2}{|c|}{$2000>P>1000$} & $P<1000$ & $P>1000$ & $P<1000$ \\
\hline Africa & $310(131-513)$ & $260(159-433)$ & $123(120-130)$ & $72(16-195)$ & 191 & 40 \\
\hline \multicolumn{7}{|c|}{ Asia \& Oceania: } \\
\hline Continental & $275(123-683)$ & $182(10-562)$ & $127(100-155)$ & 60 & $222(81-310)$ & 50 \\
\hline Insular & $348(280-520)$ & 290 & 160 & 70 & $362(330-505)$ & 50 \\
\hline America & 347 (118-860) & 217 (212-278) & $212(202-406)$ & $78(45-90)$ & $234(48-348)$ & 60 \\
\hline \multicolumn{7}{|c|}{ Note: Data are given in mean value and as range of possible values (in parentheses) } \\
\hline \multicolumn{7}{|c|}{ P: Annual Precipitation } \\
\hline
\end{tabular}

high resolution remote sensing data could thus be restricted to small hot spots to get detailed insight in the spatial development of forest cover. While high resolution sensors provide information on forest cover for small areas, the very high cost associated with their application renders their use on extensive areas not feasible. Regarding the needs for the REDD-FORECA project, sensors with different spatial resolutions needed to be integrated in order to provide a manageable and affordable spatial database.

In the recent past the capabilities of the sensor MODIS regarding the classification of forests have been intensively tested and discussed (Kleinn 2002, Bucha and Stibig 2008, Andersson and Richards 2009, FAO 2009). Hansen et al. (2008) used MODIS data to generate a regional forest/ non-forest cover map in the Congo Basin. Moat and Smith (2007) produced an atlas of the vegetation of Madagascar based on MODIS data. Despite the fact, that this data source has a spatial resolution of 250 $\mathrm{m}$ and thereby does not allow for exact area and area change calculations due to the mixed pixel issue, FAO proposes its use for monitoring in an integrated approach with higher resolution data (FAO 2007). This integration was implemented in the applied top-down approach.

In addition, Shuttle Radar Topography Mission (SRTM) data were used. This active sensor provides data on topographic information. Data from this sensor are available from the U.S. Geological Survey (USGS) free of charge and have been used since 2000 (Toutin and Gray 2000, van Zyl 2001). An adequate source on climatic information for Madagascar is the classification in climate zones by cornet (1974). Unfortunately, available national forest inventory (NFI) results of the 1990s were only of limited use, as neither complete original data sets could be obtained nor did the available data fulfil the requirements for REDD.
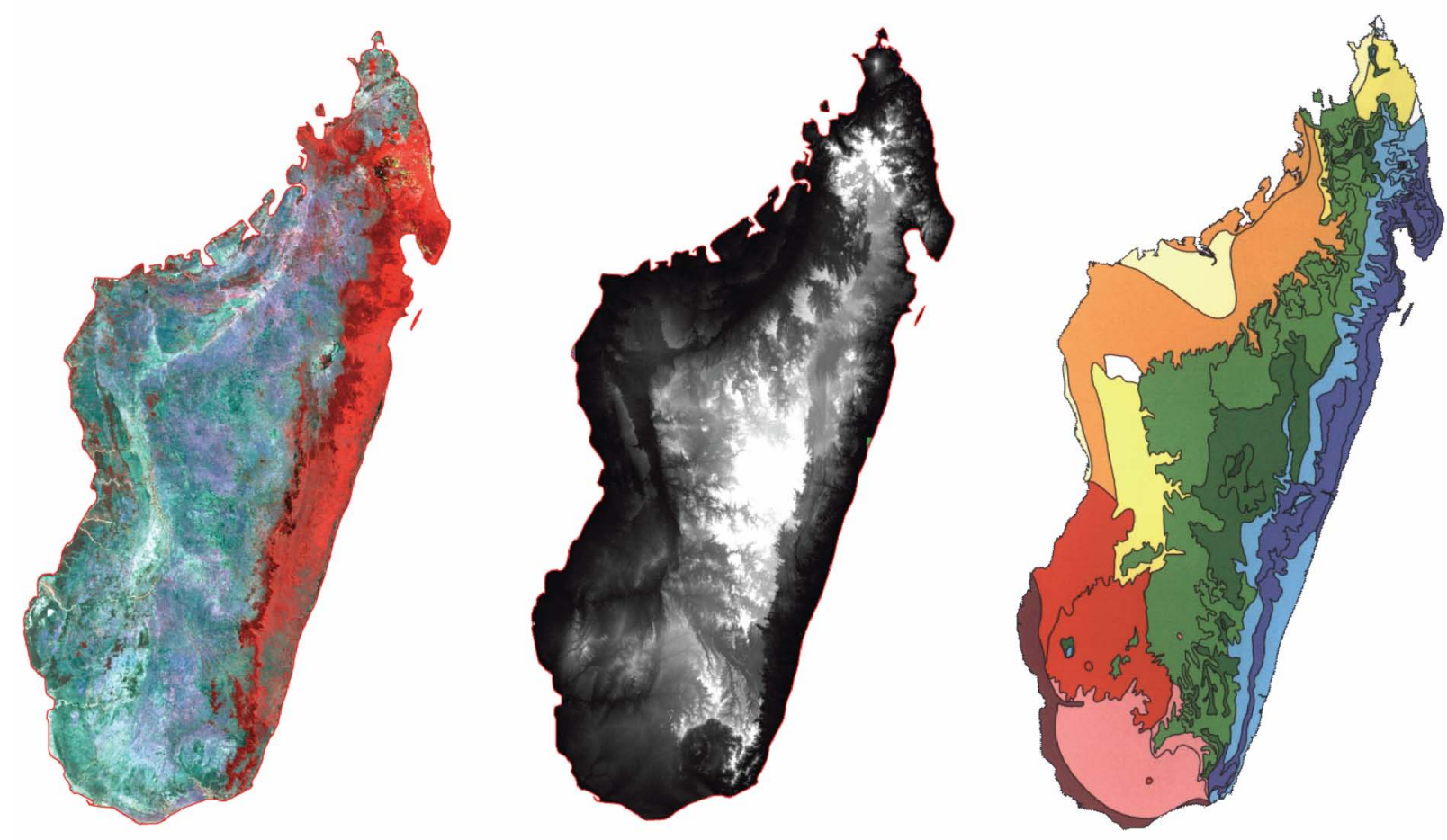

FIGURE 2. Input data for the supervised classification (from left to right): Layer stack of MODIS_13q1 (2-3-1) dated 2007-08-29, SRTM-data (darker spots represent lower areas), climate map based on cornet (1974). 
Furthermore, a criteria list was developed to identify assessment areas. In this list the prerequisites for the selection of an assessment area were defined according to their importance. First, the assessment area has to be representative for the above derived regions. Second, the derived results should be transferable to areas with similar characteristics in other tropical countries. Third, the assessment area has to exhibit different intensities of deforestation and forest degradation. Furthermore, criteria like infrastructure, accessibility and temporal feasibility were included. Considering the above named criteria and due to time restrictions a further aggregation of the categories proposed by IPCC to only three categories was realised and resulted in the following regionalisation of the country and subsequent identification of three assessment areas (see Figure 3 and Table 3).

STRATIFICATION OF ASSESSMENT AREAS. In a next step

forest areas within the assessment areas had to be identified. Here, an unsupervised classification algorithm, where RS-data is classified into spectrally similar clusters, was applied. This classification method is performed automatically, and in contrast to the above illustrated supervised classification, no reference data is used for the procedures. As a result, the RS-data is divided into a selected number of categories with similar characteristics of their radiometric information. In order to determine the number of radiometric separable classes for the assessment areas, scatter diagrams were used, where the combination of applied spectral bands of the RS-data was examined.

This classification based on the assessment areas has a high potential for error reduction as the classification results were used for stratification. The aim of this stratification was to identify forest and non-forest areas in the assessment areas. Data of the passive, high resolution SPOT 4 and SPOT 5 sensors were used. Both sensors record four spectral bands, i.e., green, red, near infra-red and short-wavelength infrared light.

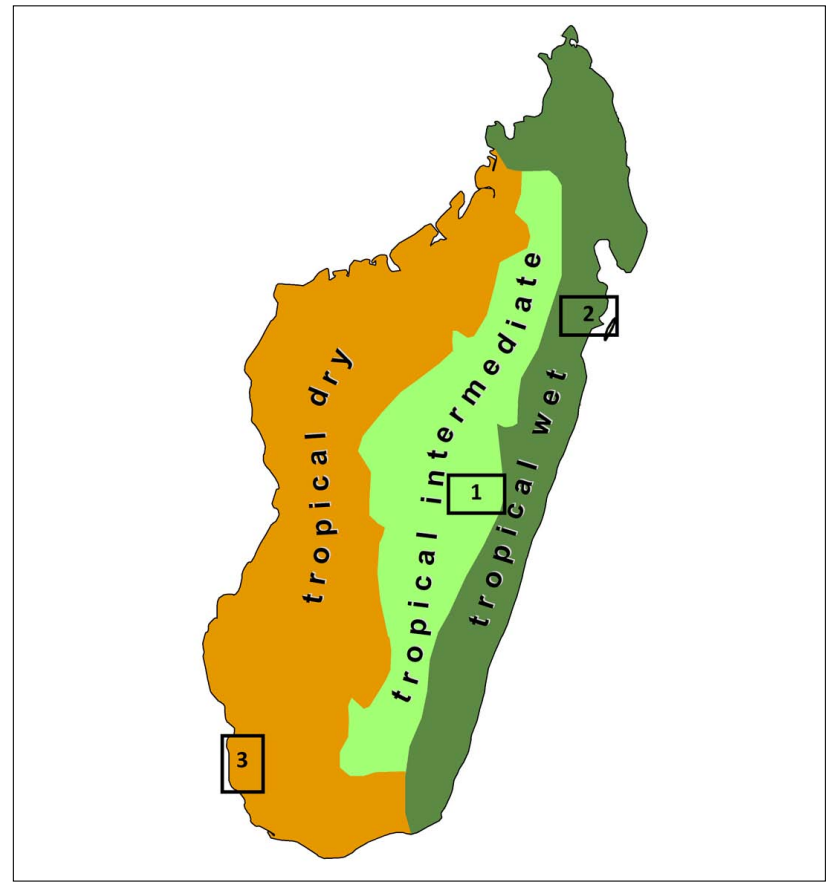

FIGURE 3. Regionalisation of Madagascar's land area based on aggregated IPCC categories; black boxes show the identified assessment areas: No. 1 Tsinjoarivo, No. 2 Manompana and No. 3 Tsimanampetsotsa.
The assessments of both forest area and carbon stock changes over time demands for repeated successive assessments. This was realised by the acquisition of remote sensing imagery from two points in time and a subsequent multi-temporal image analysis. In medium and high resolution imagery changes of the spatial distribution of forest areas were identified, while very high resolution imagery facilitated the identification of advanced stages of forest degradation. Performing a change detection analysis for the archive and the present data permitted statements on the development of these forest areas.

The primarily result was a number of intermediate classes in these forest areas, which in a second step had to be fused into the classes forest and non-forest following the parameters of the chosen forest definition. It was detected that in Madagascar two diverse types of forest fragments exist. Firstly, contiguous or almost contiguous forest areas, i.e., nearly one large forest fragment, could be detected. Secondly, small, more fragmented forest areas were identified. These circumstances gave the reason for the need for a flexible methodology, in order to keep total errors in the inventory low. Keeping errors in a reasonable scale generally requires more expenses for the field assessment. These fragments of forest were subsequently inventoried within the in-situ assessment, which was implemented in order to get sensitive information on forest degradation, i.e., the development of forest carbon stock, and to be able to quantify the loss of biomass due to deforestation activities.

IN-SITU ASSESSMENT. Cluster sampling was applied to facilitate the acquisition of field data in remote and hard to access areas on the one hand and to lower the cost of the field survey on the other hand. In more fragmented forest areas cluster sampling yields the flexibility to be adapted to area specific conditions. Two different cluster layouts for the identified assessment areas (see Figure 4) were applied. In general, different cluster layouts may also be applied for different strata within one assessment area but not within a single stratum. On the sample plots (SPS) of these clusters a multitude of data was assessed during the in-situ assessments from September 2007 to October 2008. These included dendrometric data, such as DBH (diameter at breast height, 1.30m), d7 (diameter at 7 meters height), total height and crown parameters. Furthermore, auxiliary data on the structure and status of the forest, the SP-location and its topographic characteristics as well as on possible human induced impacts were collected. Data on young forest or regeneration were obtained on special plots (small squares in Figure 4).

POST-STRATIFICATION. Using the data of the entity of sample plots (dendrometric and auxiliary) a post-stratification was applied to the population. Post-stratifications generally aim

TABLE 3. Description of the three assessment areas.

\begin{tabular}{|l|l|l|}
\hline $\begin{array}{l}\text { 1: Tsinjoarivo } \\
\text { (TJV) }\end{array}$ & $\begin{array}{l}\text { 2: Manompana } \\
\text { (MPA) }\end{array}$ & $\begin{array}{l}\text { 3:Tsimanampetsotsa } \\
\text { (TMP) }\end{array}$ \\
\hline $\begin{array}{l}\text { Semi-decidous } \\
\text { rainforest located } \\
\text { in the 'Haute Plateau' } \\
\text { of Madagascar }\end{array}$ & $\begin{array}{l}\text { Wet rainforest at the } \\
\text { east-coast of } \\
\text { Madagascar }\end{array}$ & $\begin{array}{l}\text { Dry forest in the } \\
\text { south-west of } \\
\text { Madagascar }\end{array}$ \\
\hline $\begin{array}{l}\text { Total area: } \\
\text { 32,272 hectares }\end{array}$ & $\begin{array}{l}\text { Total area: } \\
46,095 \text { hectares }\end{array}$ & $\begin{array}{l}\text { Total area: } \\
43,296 \text { hectares }\end{array}$ \\
\hline $\begin{array}{l}\text { In-situ assessment } \\
\text { from October to } \\
\text { November } 2007\end{array}$ & $\begin{array}{l}\text { In-situ assessment } \\
\text { from April to May 2008 }\end{array}$ & $\begin{array}{l}\text { In-situ assessment } \\
\text { conducted from } \\
\text { September to October } \\
\text { 2008 }\end{array}$ \\
\hline
\end{tabular}




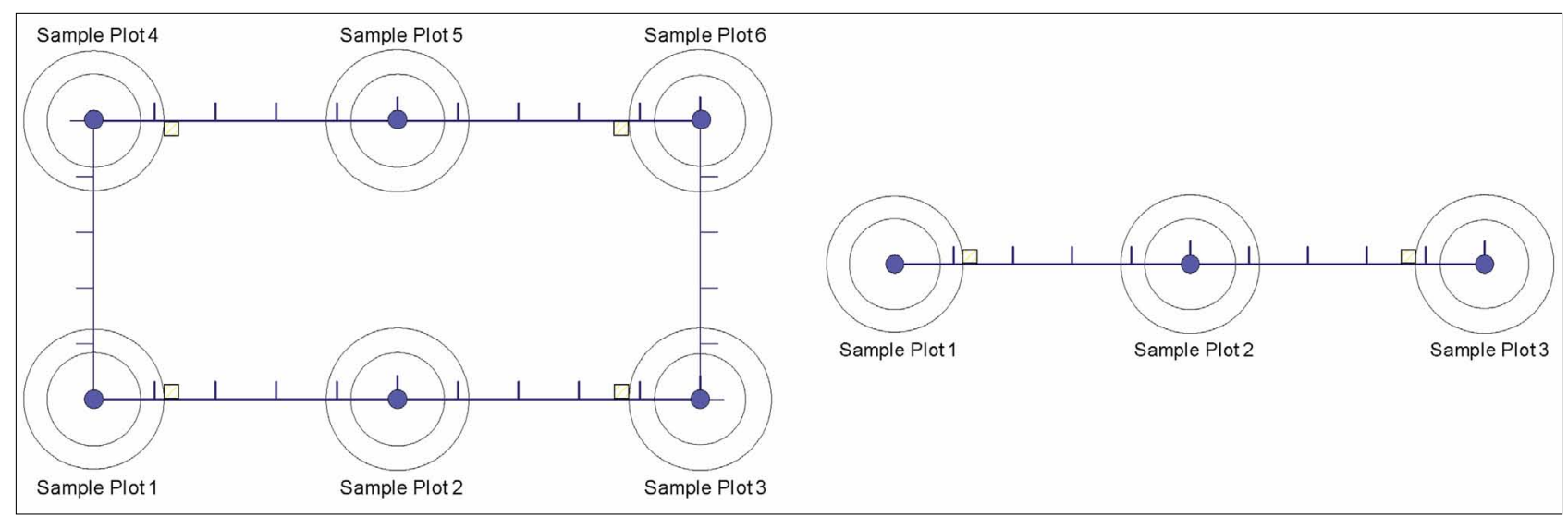

FIGURE 4. Cluster layouts applied in the REDD project in Madagascar; left for nearly pristine forests; right for highly fragmented forests. Distances between sample plots and sample plot size may also be adapted.

at producing sampling estimates with a lower sampling error for each stratum. While strata are physically connected, domains can be described as groups with specific characteristics that are found throughout the whole population, i.e., members of different domains can be found on one single SP. In the presented survey a distinction between different domains was achieved.

Nevertheless, a valid post-stratification is depending on the discriminability of the collected and examined data and can not be forced. Hence, this step is not an indispensable prerequisite for the following.

ABOVEGROUND BIOMASS. The combined inventory focuses on the calculation of living aboveground biomass (AB). There are numerous ways to derive $A B$ depending on the scale of the inventory, i.e., local, regional, or national, or the data available for a specific scale (Köhl 1998, IPCC 2006, Somogyi et al. 2007).

In the presented study, single tree volume was derived via segmentation of each tree and the appliance of domainspecific taper functions. The tree was divided into three parts: main stem (bole), the top, and the stump section. While the stump and the top represent just one single segment, the bole itself can have multiple segments, each with a different taper. Calculation of the volume of each part is presented here for the example of the second assessment area, but was similarly done in the other assessment areas with alterations regarding the area specific domains.

Volume of the bole (Vole):

$$
\mathrm{V}_{\text {bole }}=\sum_{\mathrm{s}=1}^{\mathrm{n}}\left(\frac{\pi^{*} 1_{\mathrm{sn}} * \mathrm{~d}_{\mathrm{sn}_{\mathrm{n}}}^{2}}{12}\right)+\left(\frac{\mathrm{d}_{\mathrm{sn}} * \mathrm{~d}_{\mathrm{sn}+1}}{4}\right)+\left(\frac{\mathrm{d}_{\mathrm{sn}+1}{ }^{2}}{4}\right)
$$

with

$$
\mathrm{d}_{\mathrm{s} n+1}=\mathrm{d}_{\mathrm{sn}} *\left(\frac{100-e^{\alpha+\frac{\beta}{\mathrm{d}_{\mathrm{n} n}}}}{100}\right)
$$

with

$\alpha$ and $\beta=$ domain-specific parameters

$\mathrm{d}_{\mathrm{s} n}=$ diameter at the beginning of segment $\mathrm{n}$

$\mathrm{d}_{\mathrm{s} n+1}=$ diameter at the end of segment $\mathrm{n}$

Isn = length of segment $n$

Volume of the top $\left(V_{\text {top }}\right)$ :

$$
\mathrm{V}_{\mathrm{top}}=\left(\frac{\pi * \mathrm{~d}_{\mathrm{sn}}^{2} *\left(\mathrm{~h}_{\mathrm{tot}}-\mathrm{h}_{\mathrm{bh}}-\mathrm{n}_{\mathrm{s}} * \mathrm{l}_{\mathrm{s}}\right)}{12}\right)
$$

with

$h_{\text {tot }}=$ total height of the tree

$\mathrm{n}_{\mathrm{s}}=$ number of segments of the tree

$h_{\text {bh }}=$ breast height

Volume of the stump $\left(V_{\text {stump }}\right)$ :

$$
\begin{aligned}
\mathrm{V}_{\mathrm{stump}}= & \left(\frac{\mathrm{h} \mathrm{bh}}{4}\right) *\left(\left(\frac{\pi^{*} \mathrm{~d}_{\mathrm{sn}_{\mathrm{-}}}^{2}}{4}\right)+\left(\left(\frac{\pi * \mathrm{~d}_{\mathrm{sn}-1}}{4}\right)^{2} *\left(\sqrt[3]{\frac{\pi^{*} \mathrm{~d}_{\mathrm{sn}}^{2}}{4}}\right)\right)\right. \\
& \left.+\left(\left(\frac{\pi^{*} \mathrm{~d}_{\mathrm{sn}}}{4}\right)^{2} *\left(\sqrt[3]{\frac{\pi^{*} \mathrm{~d}_{\mathrm{sn}-1^{2}}}{4}}\right)\right)+\left(\frac{\pi^{*} \mathrm{~d}_{\mathrm{s}_{n}}^{2}}{4}\right)\right)
\end{aligned}
$$

with

$$
\mathrm{d}_{\mathrm{sn}-1}=\frac{\mathrm{d}_{\mathrm{sn}}}{\left(\frac{100-e^{\alpha+\frac{\beta}{h_{\mathrm{bh}}}}}{100}\right)}
$$

with

$\alpha$ and $\beta=$ domain-specific parameters

$\mathrm{d}_{\mathrm{sn}-1}=$ diameter on ground level

The aboveground biomass of a single tree ( $A B$ tree) was derived using the above formulas as an input for:

$$
\mathrm{AB}_{\text {tree }}=\left(\mathrm{V}_{\text {stump }}+\mathrm{V}_{\text {bole }}+\mathrm{V}_{\text {top }}\right) * \mathrm{BF}
$$

with:

$\mathrm{BF}=$ species specific biomass factor

The species specific biomass factor (BF) was taken from existing literature, such as Brown (1997) or IPCC (2006). Otherwise default values for tropical hard- or softwoods provided by IPCC (2006) have been applied.

Conversion of biomass into carbon can likewise be done by means of equation factors. The more specific these equation factors are for different regions, the more elaborate the results will be. If no detailed information is available or the collection of a reasonable number of samples for wood density is too laborious, IPCC (2006) provides default values to convert biomass into carbon.

UPSCALING PROCEDURES. The aboveground biomass (AB) for a single tree was obtained by the equations described above. The sum of the $A B$ for all trees of one sample plot (SP) results in the total $A B$ for this SP. The sum of all SPS of one cluster as well as the associated variance and sampling error are derived on the basis of the single tree values. This holds as long as the 
cluster size is kept constant. Procedures to derive variances and sampling errors for unequal cluster sizes are described in cochran (1977). Upscaling procedures expand cluster data to area related estimates resulting in an aggregation of the respective values, variances, and errors on different scales (e.g., forest fragments, strata, or country). Details of the applied upscaling procedures are described in Riedel (2008). After appliance of these procedures sound and sensitive estimates of forest biomass were derived.

QUANTIFYING THE AMOUNT OF REDUCED $\mathrm{CO}_{2}$ EMISSIONS.

Quantification of the amount of reduced $\mathrm{CO}_{2}$ emissions is essential to any country that wants to commit itself to a REDD regime. This includes two important components: (1) There has to be a reference level (i.e., a baseline), against which the changes of carbon stocks in forests are set off. Different possibilities for the construction of reference scenarios are given in the specific literature (Griscom et al. 2009, Krug et al. 2009). (2) There has to be a monitoring of the development of the carbon stocks. This is provided by the presented methodology. The amount of reduced emissions can then be derived with the difference between the assumed carbon stock at the end of the commitment period referring to the selected reference level and the carbon stock estimation derived from the applied methodology.

\section{RESULTS}

Based on the IPCC categories for the zone 'Tropical Forests' a stratification in 'wet', 'intermediate' and 'dry' was achieved using a forest cover change detection algorithm (see section Regionalisation of the land area of Madagascar) and for each strata an assessment area was identified (see Table 3 and Figure 3). Combined inventories were carried out in all three assessment areas. The following table (Table 4) presents the results for the assessment areas, derived with the above described methodology. Three different domains were identified, i.e., 'Closed Forest' (crown cover $\geq 20 \%$ ), 'Open Forest' (crown cover $\geq 10 \%$ and $<20 \%$ ) and 'Non Forest' (crown cover $<10 \%$ ). The estimated means of the first two domains were tested for statistical significant differences on the $95 \%$ confidence level using a t-test. Furthermore, these estimates are combined in the domain 'Forest total'. As only clusters within forest or forest fragments were included in the field survey, there is no further terrestrial information on the domain 'Non Forest' assuming that there is no considerable amount of biomass.

For the Tsinjoarivo assessment area (see Figure 3, No. 1), the values for the mean aboveground biomass (AB) for 'Closed Forest' and 'Open Forest' are not significantly different (190.3 to $154.0 \mathrm{t} / \mathrm{ha}$ ) from each other. The area fraction for 'Closed Forest' is small; the intra-cluster-correlation coefficients (ICCS) for all domains of this assessment area are relatively high. The 'Non Forest' area is disproportionately high. The estimate for mean $A B$ for the combined domain 'Forest total' is $163.7 \mathrm{t} / \mathrm{ha}$.

For the assessment area of Manompana (see Figure 3, No. 2) the differences between the mean AB of 'Closed Forest' (293.2 t/ ha) and 'Open Forest' (184.0 t/ ha) are significant. The amount of sample plots in 'Closed Forest' is considerably higher than in 'Open Forest'. The ICC ranges from 0.18-0.28. The 'Non Forest' area accounts for $25 \%$ of the total area. The resulting estimate for 'Forest total' is $272.5 \mathrm{t}$ / ha.

The mean $A B$ in the domain 'Closed Forest' in Tsimanampetsotsa (see Figure 3, No. 3) is $136.1 \mathrm{t} /$ ha and significantly different to the estimate for the domain 'Open Forest' (mean AB 87.7 $\mathrm{t} / \mathrm{ha}$ ). More than one third of the sample plots is in the domain 'Non Forest'. The ICC ranges from 0.15-0.32. The estimate for 'Forest total' in Tsimanampetsotsa is $98.9 \mathrm{t} / \mathrm{ha}$.

TABLE 4. Estimates for each of the three assessment areas.

\begin{tabular}{|c|c|c|c|c|c|c|c|c|}
\hline \multicolumn{9}{|l|}{ Tsinjoarivo } \\
\hline Domain & n_SP & $\begin{array}{l}\mathrm{AF} \\
\text { (ha) }\end{array}$ & $\begin{array}{l}\text { SE of AF } \\
(\%)\end{array}$ & $\begin{array}{l}\text { AB total } \\
\text { (t) }\end{array}$ & $\begin{array}{l}\text { SE of AB total } \\
\text { (\%) }\end{array}$ & $\begin{array}{l}\text { Mean } A B \\
\text { (t/ha) }\end{array}$ & $\begin{array}{l}\text { SE of mean } A B \\
(\%)\end{array}$ & ICC \\
\hline Closed Forest & 15 & 495 & 31.0 & 94,169 & 31.7 & 190.3 & 34.2 & 0.72 \\
\hline Open Forest & 41 & 1,353 & 18.9 & 208,302 & 19.8 & 154.0 & 23.7 & 0.73 \\
\hline Forest total & 56 & 1,848 & 19.0 & 302,471 & 20.0 & 163.7 & 23.9 & 0.78 \\
\hline Non Forest & 922 & 30,424 & 1.2 & & & & & \\
\hline \multicolumn{9}{|l|}{ Manompana } \\
\hline Domain & n_SP & $\begin{array}{l}\mathrm{AF} \\
\text { (ha) }\end{array}$ & $\begin{array}{l}\text { SE of AF } \\
(\%)\end{array}$ & $\begin{array}{l}\text { AB total } \\
(\mathrm{t})\end{array}$ & $\begin{array}{l}\text { SE of AB total } \\
\text { (\%) }\end{array}$ & $\begin{array}{l}\text { Mean } A B \\
\text { (t/ha) }\end{array}$ & $\begin{array}{l}\text { SE of mean } A B \\
(\%)\end{array}$ & ICC \\
\hline Closed Forest & 47 & 28,136 & 12.4 & $8,250,251$ & 13.1 & 293.2 & 29.5 & 0.27 \\
\hline Open Forest & 11 & 6,585 & 32.4 & $1,211,540$ & 32.0 & 184.0 & 43.0 & 0.18 \\
\hline Forest total & 58 & 34,721 & 9.4 & $9,461,790$ & 10.2 & 272.5 & 25.5 & 0.28 \\
\hline Non Forest & 19 & 11,374 & 28.8 & & & & & \\
\hline \multicolumn{9}{|c|}{ Tsimanampetsotsa } \\
\hline Domain & n_SP & $\begin{array}{l}\text { AF } \\
\text { (ha) }\end{array}$ & $\begin{array}{l}\text { SE of AF } \\
(\%)\end{array}$ & $\begin{array}{l}\text { AB total } \\
\text { (t) }\end{array}$ & $\begin{array}{l}\text { SE of AB total } \\
\text { (\%) }\end{array}$ & $\begin{array}{l}\text { Mean } A B \\
\text { (t/ha) }\end{array}$ & $\begin{array}{l}\text { SE of mean } A B \\
(\%)\end{array}$ & $\mathrm{ICC}$ \\
\hline Closed Forest & 21 & 6,448 & 23.8 & 877,889 & 27.5 & 136.1 & 34.7 & 0.22 \\
\hline Open Forest & 70 & 21,494 & 9.1 & $1,885,991$ & 9.5 & 87.7 & 23.0 & 0.15 \\
\hline Forest total & 91 & 27,943 & 8.7 & $2,763,880$ & 11.6 & 98.9 & 18.5 & 0.32 \\
\hline Non Forest & 50 & 15,353 & 15.9 & & & & & \\
\hline
\end{tabular}


TABLE 5. Aggregation of estimates on country level.

\begin{tabular}{|l|l|l|l|l|l|l|l|}
\hline Madagascar & n_SP & $\begin{array}{l}\text { AF } \\
\text { (ha) }\end{array}$ & $\begin{array}{l}\text { SE of AF } \\
(\%)\end{array}$ & $\begin{array}{l}\text { AB total } \\
\text { (t) }\end{array}$ & $\begin{array}{l}\text { SE of AB total } \\
(\%)\end{array}$ & $\begin{array}{l}\text { Mean AB } \\
\text { (t/ha) }\end{array}$ \\
\hline Closed Forest & 83 & 35,079 & 10.9 & $\begin{array}{l}\text { SE of mean AB } \\
(\%)\end{array}$ & $9,222,309$ & 12.0 & 262.9 \\
\hline Open Forest & 122 & 29,432 & 9.9 & $3,305,832$ & 13.0 & 112.3 & 194.2 \\
\hline Forest total & 205 & 64,512 & 6.4 & $12,528,141$ & 8.2 & 20.6 & 20.1 \\
\hline Non Forest & 991 & 7.2 & & & \\
\hline n_SP = number of sample plots; AF = area fraction; SE = standard error; AB = aboveground biomass; $t=$ ton; ha $=$ hectar \\
\hline
\end{tabular}

Table 5 shows the aggregation of the estimates for the three assessment areas as presented above on country level for Madagascar. Consequently the apportionment into three domains ('Closed Forest', 'Open Forest', 'Non Forest') and the combination of 'Closed Forest' and 'Open Forest' as 'Forest total' again is applied. For the aggregation on country level no ICC as a measure of the efficiency of cluster sampling is calculated, because sensible results can only be expected for the assessment area level.

The estimates for 'Closed Forest' (262.9 t/ ha) and 'Open Forest' (112.3 t/ha) on national scale are significantly different from each other. The estimate for mean aboveground biomass for the combined domain 'Forest total' is 194.2 t/ ha. The overall sampling error (SE of mean $A B$ ) ranges from $26.6 \%$ to $20.1 \%$ decreasing with increasing sample size.

\section{DISCUSSION}

The applied methodology displays the adaptation of fully operational and respected methods to the particular needs of a possible REDD regime for Madagascar. The application of remote sensing analyses for the top-down approach using medium resolution imagery and sensible auxiliary data forthe regionalisation of the land area of Madagascar and a first stratification into forest and non-forest areas proved to be feasible. The identification of hot spots of deforestation utilizing change detection analysis with different points in time led to a sound and sensible selection of appropriate assessment areas. A further stratification of these areas e.g., into the strata closed forest and open forest, could have been possible by means of very high resolution imagery. However, this was not feasible in this project due to disadvantageous RS-data quality. Nevertheless, utilizing expensive, very high resolution imagery not for the entire country but only for the identified assessment areas helps to keep costs at a manageable level.

The systematic sampling approach incorporating cluster sampling for the in-situ assessment proved to be operational for remote and hard to access as well as highly fragmented forest areas. The physical conduction of the in-situ method and the subsequent calculation of single tree biomass as well as the applied upscaling methods led to sound and reliable estimates on aboveground biomass for each of the assessment areas which are discussed in the following.

ESTIMATES FOR THE THREE ASSESSMENT AREAS.

The non-significance in the difference of the estimates for mean aboveground biomass (AB) (see Table 4) in the assessment area Tsinjoarivo as well as the high intra-cluster-correlation coefficient (ICC) is caused by the high fragmentation and degradation of the forest. The high amount of sample plots in the domain 'Non Forest' is owed to the same reason and enhanced by the fact that at the time of planning only outdated data from the national forest inventory (NFI) from 1996 were available as reference. This resulted in a conservative layout of the sampling grid $(1 \mathrm{~km} \times 2 \mathrm{~km})$. The estimate for the combined domain 'Forest total' meets the IPCC values for the adapted category 'intermediate (semi-dry / semi-wet)' forests (see Table 2).

The ICC for the assessment area Manompana is justifiable in the scope of a pilot project. The estimate for the domain 'Forest total' is within the range of possible values for the adapted IPCC category 'wet' (310 to 272.5 t/ ha). The sampling error could be reduced significantly if the applied method would be adjusted to a national scale inventory, thus augmenting the sampling intensity in this category.

The ICC in the assessment area of Tsimanampetsotsa is acceptable for a pilot project. The estimate for the adapted IPCC category is well within the range of possible values (see Table 2). The error of the estimates in this area is also acceptable for a pilot project.

The estimate aggregated on country level for the domain 'Forest total' (194.2 t/ha) meets the default value for aboveground biomass content in forest in 2000 given by IPCC in table 3A.1.4 of the GPGLULUCF for Madagascar (194 t/ha) (IPCC 2003). The sampling error for the mean $A B$ in this domain is acceptable for a pilot project but is likely to be reduced if the applied assessment scheme would be extended on a national scale. This would imply an extension of the in-situ assessment to more than the three selected assessment areas, resulting in higher costs for the combined inventory.

RELIABILITY OF ESTIMATES. The assessment of carbon

stock and carbon stock changes is associated with uncertainties. The IPCC GPG LULUCF (IPCC 2003) addresses this problem by offering parties to use three different tiers (i.e., levels of reliability) for their national greenhouse gas reporting. Where parties want to generate carbon credits by participating in REDD, the reliable minimum estimate (RME) for carbon stock changes needs to be presented in order to follow the broadly accepted principle of conservativeness (Grassi et al. 2008). A point estimate of the carbon stock or its change rate over time needs to be supplemented by a quantitative measure of its reliability. The point estimate is reduced by the reliability measure resulting in the RME; not the point estimate but the RME qualifies for accounting. Therefore parties are obliged to report on the errors associated with any carbon estimate and need to implement assessment methods that result in estimates with high reliability to render possible the generation of benefits from REDD (Köhl et al. 2009). The reliability of forest area changes is quantified via the accuracy of remote sensing classifications, while 
the reliability of biomass estimates results from the calculation of sampling error estimates. Errors associated with the assessment of individual tree biomass and its conversion into carbon contents are to be obtained by empirical studies. All different error sources can be combined via an error budget (Gertner and Köhl 1992) and allow for a consistent and accepted quantification of the reliability of carbon stocks and carbon stock changes.

COMBINATION OF REMOTE SENSING DATA AND IN-SITU

ASSESSMENTS. The use of satellite imagery and remote sensing techniques has been widely described as an efficient tool to monitor forest area changes (Bowden et al. 1979, UN-ECE/FAO 2000). Remote sensing provides spatially explicit data on forest areas and allows for multi-temporal approaches on forest area changes and can thereby be used in the scope of REDD (GOFC-GOLD 2009).

Apart from detectable and quantifiable deforestation in the applied remote sensing phase the applied in-situ methodologyallows to gather sensitive information on forest degradation, as well. The importance of including degradation in REDD is stated in international discussions (UNFCCC 2008).

Variable extents of forest degradation still make its assessment a challenging task (Baldauf et al. 2009, FAO 2009). In addition, optical remote sensing sensors fall short when it comes to the assessment of minor changes in standing woody biomass (Scott and Köhl 1994). Especially in natural forests in the tropics and subtropics, which are characterised by heterogenic vertical stand structures and contiguous canopy covers, degradation can only be detected, when the formerly closed canopy cover is dissolved. Otherwise, if the forest is degraded affecting the canopy cover in a minor extent only, the degradation remains stealthy for optical remote sensing sensors (see Figure 5). So far, this stealthy degradation can only be assessed by field surveys.

Although clear definitions of degradation are yet missing the applied methodology is designed to be flexible enough for adaptation to a finally agreed definition of forest degradation.

\section{CONCLUSION}

On the one hand the applied methodology depends largely on capacities which have to be available or which have to be build up in a country applying for REDD. Not later than at the end of the first commitment period all capacities should be available in the specific country so that there is no urgent need for broad scale consultancy. On the other hand country specific knowledge is indispensable when generating such an approach. The applied methodology was developed in close collaboration of the Forest
Institute of the University of Antananarivo (ESSA Forêts) and the Institute for World Forestry at the VTI in Hamburg, thus guaranteeing the incorporation of country specific knowledge.

A broadly accepted challenge lies in the most effective combination of remote sensing and terrestrial inventories. For the RS-data and further additional data, e.g., national forest inventory (NFI), data availability will differ from country to country. Therefore, the applied methodology uses RS-data that is available worldwide, e.g., MODIS, or identifies sensor categories, i.e., medium, high and very high resolution data.

The results of this pilot study show that the applied combined inventory and the upscaling methods are capable of producing reliable results on a national level. Regarding the need for successive inventories in the scope of REDD the in-situ design can be further optimised for each of the adapted IPCC categories on the basis of the presented results to fully exploit the advantages of a systematic stratified cluster sampling design.

Concerning the detection of degradation areas, problems arise from the small scale differences in RS-data. The availability of cloudless very high resolution data can be considered as a big challenge, especially in the tropics. Presently, there are some projects using high resolution RADAR data (i.e., TerraSAR-X), which could possibly overcome these challenges.

\section{CONTRIBUTIONS \& ACKNOWLEDGEMENTS}

DP, TB and MK developed the methodology and statistical background aligned to it. DP carried out the terrestrial implementation of the methodology, TB conducted the remote sensing analyses. HRR and GR adapted the methodology to the specific conditions found in Madagascar.

We would like to thank all partners in the REDD-FORECA project, namely GTZ, PGM-E Madagascar, Intercooperation Suisse and MEEFT. Thanks must be extended to the BMELV, Germany, donor of VTI. We also thank our colleagues Aziza Rqibate, Dr. Thomas Riedel, Dr. Wolf-Ulrich Kriebitzsch, Dr. Bettina Leischner and Dr. Matthias Dieter for numerous rewarding discussions and comments, and Nadine Geigle for preparing the figures.

We are grateful to three anonymous reviewers, which helped to improve the quality of the text.

\section{REFERENCES}

Achard, F., Eva, H. D., Stibig, H.-J., Mayaux, P., Gallego, J., Richards, T. and Malingreau J. P. 2002. Determination of deforestation rates of the world's humid tropical forests. Science 297:999-1002. (doi:10.1126/ science.1070656)

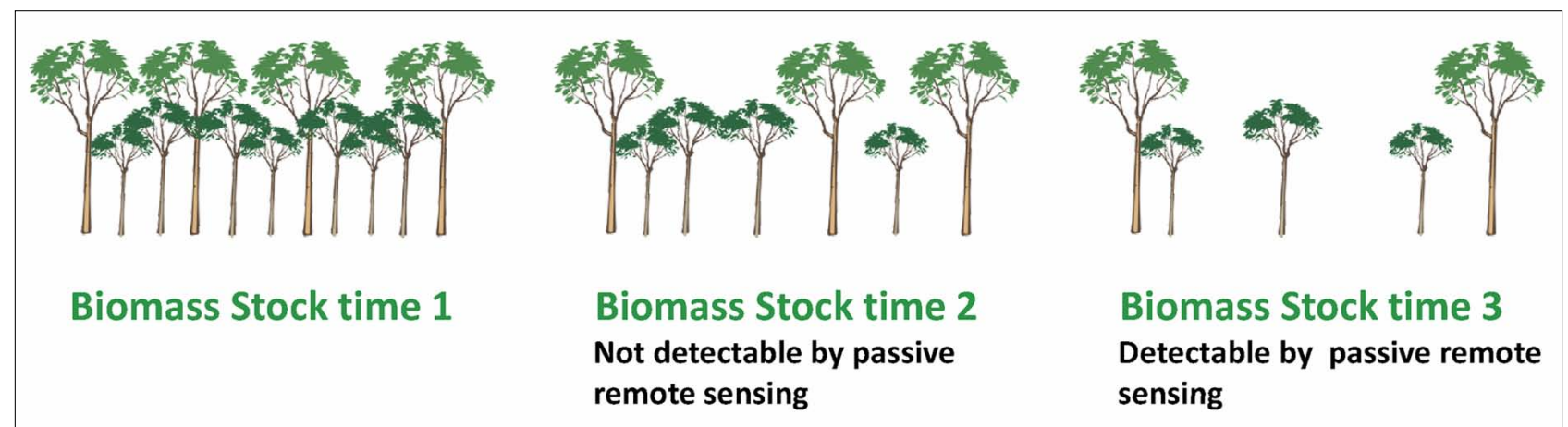

FIGURE 5. Different status of forest degradation and potential of detection by optical remote sensing techniques (Baldauf et al. 2009). 
Adlard, P. G. 1990. Procedures for Monitoring Tree Growth and Site Change. A Field Manual. Oxford Forestry Institute. Department of Plant Sciences. University of Oxford.

Andersson, K., Evans, T. P. and Richards, K. R. 2009. National forest carbon inventories: Policy needs and assessment capacity. Climate Change 93: 1-2, 69-101. (doi:10.1007/s10584-008-9526-6)

Baldauf, T., Plugge, D., Rqibate, A. and Köhl, M. 2009. Monitoring degradation in the scope of REDD. Case Studies on Measuring and Assessing Forest Degradation. Forest Resources Assessment Working Paper 162. Rome. Available at <http://www.fao.org/docrep/012/k7612e/k7612e00.pdf>

Bellamy, P. H., Loveland, P. J., Bradley, R. I., Lark, R. M. and Kirk, G. J. D. 2005. Carbon losses from all soils across England and Wales 1978-2003. Nature 437: 245-248. (doi:10.1038/nature04038)

Bowden, C. A., Dixon, G. E., Frayer, W. E., Graybill, F. A., Jeyaratnam, S., Johnston, D. C., Kent, B. M., Labau, V. J. and Roberts E. 1979. Multi-Leve Sampling Designs for Ressource Inventories. Dept. of Forest and Wood Sciences, Colorado State University, Rocky Mountain Forest and Range Experiment Station, USDA Forest Service, Ft. Collins, CO

Brown, S. 1997. Estimating Biomass and Biomass Change in Tropical Forests. A primer. FAO Forestry Paper 134. Rome.

Bucha, T. and Stibig, H.-J. 2008. Analysis of MODIS imagery for detection of clear cuts in the boreal forest in north-west Russia. Earth Observations for Terrestrial Biodiversity and Ecosystems Special Issue. Remote Sensing of Environment 112. 5: 2416-2429. (doi:10.1016/ j.rse.2007.11.008).

Cochran, W. G. 1977. Sampling Techniques. J. Wiley \& Sons, New York.

Cornet, A. 1974. Essai de cartographie bioclimatique à Madagascar. Carte à l'échelle de 1/2000 000 et notice explicative No 55. ORSTROM, Paris.

DeFries, R., Achard, F., Brown, S., Herold, M., Murdiyarso, D., Schlamadinger, B. and De Souza C. 2006. Reducing Greenhouse Gas Emissions from Deforestation in Developing Countries: Considerations for Monitoring and Measuring. Report of the Global Terrestrial Observing System (GTOS) number 46, GOFC-GOLD report 26.

Denman, K. L., Brasseur, G., Chidthaisong, A., Ciais, P., Cox, P. M., Dickinson R. E., Hauglustaine, C., Heinze, E., Holland, D., Jacob, U., Lohmann, S., Ramachandran, P. L., da Silva Dias, D., Wofsy, S. C. and Zhang X. 2007. Couplings Between Changes in the Climate System and Biogeochemistry. In: Solomon, S., Qin, D., Manning, M., Chen, Z., Marquis, M., Averyt, K. B., Tignorand, M. and Miller, H. L. (eds.), Climate Change 2007, pp 541-584. The Physical Science Basis. Contribution of Working Group I to the IPCC Fourth Assessment. Report of the Intergovernmental Panel on Climate Change. Cambridge University Press, Cambridge, UK and New York, USA.

FAO 2007. Options and recommendations for a global remote sensing survey of forests. Global forest resources assessment 2010. With collaboration of Ridder, R. M. and Løyche Wilkie, M.. Rome (Forest Resources Assessment Working Paper, 141). Available at <http://www. fao.org/forestry/16678-1-0.pdf>.

FAO 2009. The FRA 2010 remote sensing survey. An outline of objectives, data, methods and approach. Forest Resources Assessment Working Paper 155. With collaboration of Løyche Wilkie, M. Rome. Available at <http://www.fao.org/docrep/012/k7023e/k7023e00.pdf>

FAO (Ed.) 2009. Case Studies on Measuring and Assessing Forest Degradation. Forest Resources Assessment Working Paper, 171. With collaboration of Løyche Wilkie, M. Rome. Available at <http://www.fao. org/docrep/012/al041e/al041e01.pdf>

Freibauer, A., Drösler, M., Gensior, A. \& Schulze, E. D. 2009. Das Potenzial von Wäldern und Mooren für den Klimaschutz in Deutschland und auf globaler Ebene [The potential of forests and peatlands to contibute to climate change mitigation in Germany and worldwide]. Natur und Landschaft 84, 1: 20-25.

Gertner, G. and Köhl, M. 1992. An assessment of some non-sampling errors in a national survey using an error budget. Forest Science 38, 3: 525-538.

GOFC-GOLD 2009. Reducing Greenhouse Gas Emissions from Deforestation and Degradation in Developing Countries: A Sourcebook of Methods and Procedures for Monitoring, Measuring and Reporting. GOFCGOLD Report version COP14-2, GOFC-GOLD Project Office, Natural Resources Canada, Alberta, Canada.
Grassi, G., Monni, S., Federici, S., Achard, F. and Mollicone, D. 2008. Applying the conservativeness principle to REDD to deal with the uncertainties of the estimates. Environmental Research Letters 3: 035005. (doi:10.1088/1748-9326/3/3/035005)

Griscom, B., Shoch, D., Stanley, B., Cortez, R. and Virgilio, N. 2009. Sensitivity of amounts and distribution of tropical forest carbon credits depending on baseline rules. Environmental Science \& Policy 12, 7: 897-911. ( doi:10.1016/j.envsci.2009.07.008)

Hansen, M. C., Roy, D. P., Lindquist, E., Adusei, B., Justice, C. O. and Altstatt, A. 2008. A method for integrating MODIS and Landsat data for systematic monitoring of forest cover and change in the Congo Basin. Earth Observations for Terrestrial Biodiversity and Ecosystems Special Issue. In: Remote Sensing of Environment 112, 5: 2495-2513. (doi:10.1016/ j.rse.2007.11.012)

IPCC 2003. Good Practice Guidance for Land Use Land Use Change and Forestry. The Intergovernmental Panel on Climate Change, IPCC/IGES Hayama, Japan.

IPCC 2006. 2006 IPCC Guidelines for National Greenhouse Gas Inventories. Prepared by the National Greenhouse Gas Inventories Programme, Eggleston, H. S., Buendia, L., Miwa, K., Ngara, T. and Tanabe K. (eds). Published: IGES, Japan.

Kleinn, C. 2002. New technologies and methodologies for national forest inventories. Unasylva 53, 210. Available at <http://www.fao.org/ docrep/005/y4001e/y4001e00.htm>

Köhl, M. 1998. National biomass survey for Zimbabwe. Outline of Activities Required to Prepare a National Biomass Survey on the Base of the VegRIS Vegetation Map Cover. Report of the Mission of Prof. Dr. Michael Köhl.

Köhl, M., Magnussen, S. S. and Marchetti, M. 2006. Sampling Methods, Remote Sensing and GIS Multiresource Forest Inventory. Springer, Heidelberg.

Köhl, M., Baldauf, T., Plugge, D. and Krug, J. 2009. Reduced emissions from deforestation and forest degradation (REDD): A climate change mitigation strategy on a critical track. Carbon Balance and Management 4: 10. (doi:10.1186/1750-0680-4-10)

Krug, J., Köhl, M., Riedel, T., Bormann, K., Rueter, S. and Elsasser, P., 2009. Options for accounting carbon sequestration in German forests. Carbon Balance and Management 4: 5. (doi:10.1186/1750-0680-4-5)

Lillesand, T. M., Kiefer, R. W. and Chipman, J. W. 2004. Remote Sensing and Image Interpretation. John Wiley \& Sons, New York.

Loetsch, F., Zoehrer, F. and Haller, K. E. 1973. Forest Inventory. Volume II. BLV Verlgasgesellschaft. München, Bern, Wien.

Longdoz, B., Aubinet, M., François, L. 2004. Model of forest carbon sequestration incorporating aerial wood radiative budget. Agricultural and Forest Meteorology 125, 1-2: 83-104.

Mandallaz, D. 2008. Sampling Techniques for Forest Inventories. Chapman \& Hall/CRC, New York.

Moat, J. and Smith, P. 2007. Atlas of the Vegetation of Madagascar. Royal Botanic Garden, Kew.

Nabuurs, G.-J. 2004. Current consequences of past actions: How to separate direct from indirect. In: The Global Carbon Cycle. Integrating Humans, Climate, and the Natural World. C. B. Field, .M. R.Raupach, (eds.), pp 317-326. Island Press, Washington, D.C.

Riedel, T. 2008. Evaluierung alternative Stichprobenkonzepte für die Bundeswaldinventur. Unpublished Ph.D. Dissertation. Department Biologie der Fakultät für Mathematik, Informatik und Naturwissenschaften. Universität Hamburg.

Saket M., Altrell, D., Branthomme, A. and Vuorinen P. 2002. FAO's Approach to Support National Forest Assessments for Country Capacity Building. Kotka IV: Expert Consultation on Global Forest Resources Assessment - Linking National and International efforts. FAO Forestry Department. Background paper 6.6.

Schlesinger, W. H. and Lichter, J. 2001. Limited carbon storage in soil and litter of experimental forest plots under increased atmospheric $\mathrm{CO} 2$ Nature 411: 466-469. (doi:10.1038/35078060)

Schoene, D., Killmann, W., von Lüpke, H. and Løyche Wilkie, M. 2007. Definitional issues related to reducing emissions from deforestation in developing countries. Forest and Climate Change Working Paper 5. FAO. Rome. 
Scott, C. T. and Köhl, M. 1994. Sampling with partial replacement and stratification. Forest Science 40, 1: 30-46.

Somogyi, Z., Cienciala, E., Mäkipää, R., Muukkonen, P., Lehtonen, A. and Weiss, P. 2007 Indirect methods of large-scale forest biomass estimation. European Journal of Forest Research 126, 2: 197-207. (doi:10.1007/s10342-006-0125-7)

Stern, N. 2007. The Economics of Climate Change. The Stern Review. Cambridge University Press, Cambridge.

Synnott, T. J. 1979. A Manual of Permanent Plot Procedures for Tropical Rainforests. Tropicla Forestry Papers No. 14. Department of Forestry. Commonwealth Forestry Institute. University of Oxford.

Toutin, T. and Gray, L. 2000. State-of-the-art of elevation extraction from satellite SAR data. ISPRS Journal of Photogrammetry and Remote Sensing 55, 1: 13-33.

UN-ECE/FAO 2000. Forest resources of Europe, CIS, North America, Australia, Japan and New Zealand. United Nations publication no E.9911. E., 36 UN-ECE, Geneva.

United Nations Framework Convention on Climate Change (UNFCCC). 1998. Kyoto Protocol to the United Nations Framework Convention on Climate Change. United Nations.

United Nations Framework Convention on Climate Change (UNFCCC). 2001. The Marrakesh Accords \& The Marrakesh Declaration. United Nations.

United Nations Framework Convention on Climate Change (UNFCCC). 2007. Bali Action Plan. Decision 1 / CP.13.

United Nations Framework Convention on Climate Change (UNFCCC) 2008. Report on the Workshop on Methodological Issues Relating to Reducing Emissions from Deforestation and Forest Degradation in Developing Countries. Tokyo, Japan.

United Nations Framework Convention on Climate Change (UNFCCC). 2009. Draft decision 4 / CP. 15. Methodological guidance for activities relating to emissions from deforestation and forest degradation and the role of conservation, sustainable management of forests and enhancement of forest carbon stocks in developing countries.

van Zyl, J. J. 2001. The Shuttle Radar Topography Mission (SRTM): A breakthrough in remote sensing of topography. Acta Astronautica, 48, 5-12: 559-565.

\section{SUPPLEMENTARY MATERIAL.}

AVAILABLE ONLINE ONLY.

Overview of methodology of combined inventory, detailed illustration of the applied combined inventory methodology showing the top-down and bottom-up approaches. 